\title{
THE IMPACT OF ONLINE ANNOTATION TOOLS ON STUDENTS' ACADEMIC PERFORMANCE IN A DISTANCE UNIVERSITY PROGRAM
}

\author{
Dr. Carmen BENITEZ \\ ORCID: 0000-0001-9745-4938 \\ Educational Sciences Department \\ Universidad Tecnica Particular de Loja \\ Loja, ECUADOR \\ Dr. Ana QUINONES \\ ORCID: 0000-0002-5722-1096 \\ Educational Sciences Department \\ Universidad Tecnica Particular de Loja \\ Loja, ECUADOR
}

Dr. Paul GONZALEZ

ORCID: 0000-0003-1964-2671

Educational Sciences Department Universidad Tecnica Particular de Loja

Loja, ECUADOR

Cesar OCHOA

ORCID: 0000-0002-9047-3180

Educational Sciences Department Universidad Tecnica Particular de Loja Loja, ECUADOR

\author{
Alba VARGAS \\ ORCID: 0000-0002-6751-719X \\ Educational Sciences Department \\ Universidad Tecnica Particular de Loja \\ Loja, ECUADOR
}

Received: 16/03/2019 Accepted: 06/05/2019

\begin{abstract}
The present study aims to test the effectiveness of the Nota Bene (NB) software as an on line annotation tool to enhance students' academic performance and to know their perceptions about the use of this tool. In this research, a quasi-experimental design was used in a private university in Ecuador. The participants were ninety-eight pre-service EFL teachers, who were trained during a five-month period and divided into two groups: control and experimental. They took a pre and a post-test at the beginning and at the end of the training period. The students from the experimental group answered a questionnaire about the perceptions on the use of NB. The statistically significant differences found in the results of the post-test indicate that NB is an effective software to enhance participants' academic performance. In addition, the students who used this tool had positive perceptions about the use of NB while doing their academic activities.
\end{abstract}

Keywords: Nota Bene (NB), students, distance learning, academic performance, perceptions 


\section{INTRODUCTION}

Today, the advances and popularity of the use of Communication and Information Technologies (ICTs) influence all fields of knowledge, one of which is education (Tezci, 2009). In this regard, technological tools are an important element in the learning process. Some of these tools allow students and teachers to interact and implement feedback in a collaborative environment. This type of technology involves annotation tools, which have advantages with positive effects on the students' learning performance; thus, enhancing the motivation to learn (Hwang, Wang \& Sharples, 2007). Their advantages include the facilitation of reading activities, highlighting or underlining information, asking and answering questions, providing feedback, sharing digital files, among others (Miller, Lukoff, King \& Mazur, 2018).

One of those annotations tools is NB, which is an in-place collaborative document annotation website used by students to read lecture notes and draft textbooks (Zyto, Karger, Ackerman \& Mahajan 2012). This tool has the advantages of adding extra materials such as sample videos, soundtracks, or other texts to specific parts of the reading material. NB also engages students more deeply in reading and allows them to know their classmates' opinion about different parts of a text to be studied in class.

Based on the aforementioned, our study is focused on testing the effectiveness of NB to enhance pre-service teachers' academic performance in a distance program as well as their perceptions on the use of this tool. $\mathrm{NB}$ was included as part of a distance learning course due to the unsatisfactory results of some pre-service teachers in their academic performance when learning the courses of the English program at the university under study.

Furthermore, in the Ecuadorian context, formal research on the use of annotation tools such as NB is scarce. For this reason, the present study attempts to fill in this gap by answering the following research questions: How effective is NB to enhance pre-service teachers' academic performance?

What are the pre-service teachers' perceptions about using NB as a tool for enhancing academic performance?

\section{LITERATURE REVIEW}

\section{Online Annotation Tools}

Online annotation tools have been developed to facilitate annotations and interaction with digital documents by means of a web annotation system, which allows users to change, add or attach any type of content to any online resource, as it is done on a paper document (Kawase, Herder, and Nejdl, 2009). Glover, Xu, and Hardaker (2007) define online annotation tools as systems that provide mechanisms to allow readers to interact (in a synchronous or asynchronous way) and to make notes on online texts; thus, facilitating deeper reading and acquisition of new levels of knowledge. Bottoni, Levialdi, and Rizzo (2003) state that these tools favor cognitive development by highlighting information to remember, adding questions, comments or critical remarks, doing collaborative work, and supporting discussions related to the text.

Nokelainen, Kurhila, Miettinen, Floreen, and Tirri (2003) discuss three generations of online annotation tools. The first one requires installation of platform-specific client-side software. The second generation, technology evolves toward a possibility to insert annotations in any type of document on the web. The third generation comprises more sophisticated systems with tools that allow long and threaded newsgroup discussion-like annotation, markers, background color, among other features (e.g. EDUCOSM).

According to Burghardt (2012), there are a lot of online annotation tools available on the web that differ in terms of the software use and the modality of annotation that they comprise (images, spoken or written text, audio or video files), as well as for the particular features and usability. Azouaou, Chen, and Desmoulins (2004) propose that in order for annotation tools to be effective in an e-learning context, they must be properly selected, considering usefulness, shareability, and usability.

\section{Online Annotation Tools and Distance University Learning}

Online learning is closely associated to distance learning. In this respect, online learning for distance students may incorporate social interaction, collaboration, and reflection (Murugaiah \& Thang, 2010). A method for 
promoting social interaction, collaboration, and reflection is the incorporation of online annotation tools, which have been widely used in the field of face-to-face, online, and distance learning. In this regard, the use of Moodle-based environments can be helpful in the case of annotation tools for providing feedback on online environments to enhance reading comprehension and critical analysis. The tools used included questionnaires, reading journals, databases, glossaries, written assignments, and wikis (Borham-Puyal \& Olmos-Miguelanez, 2011). Another case of annotation tools is the highlight tool, which allows students to mark important information that can be easily found later. In addition, the highlighted information can be shared online for revision and edition by other users (Nunes, Kawase, Dietze, de Campos, \& Nejdl, 2012). Another advantage of online annotation tools and online learning is the facilitation of collaborative learning. Social online tools such as Diigo have been proven to be effective in collaborative learning activities when working with online texts (Gao, 2013). This effectiveness of collaborative learning can also be observed in reading activities that can be facilitated by the social annotation platforms such as Perusall, which can be used by the students to do pre-reading activities while discussing the information to be read online; thus, promoting active reading strategies and generating learning interactions among students (Miller, Lukoff, King \& Mazur, 2018).

\section{Nota Bene as an Annotation Tool}

Nota Bene (NB) is a web-based collaborative annotation tool designed by David Karger and Sasha Zyto, who are members of the Haystack Group in the Computer Science and Artificial Intelligence Laboratory at Massachusetts Institute of Technology (MIT).

According to Zyto et al. (2012), NB is an in-place collaborative document annotation website used by students to read lecture notes. It also allows its users to interact through questions and answers (as a discussion space at the margins of the digital material provided for reading), to submit their reading assignments, and to obtain or give feedback.

$\mathrm{NB}$ is used as an annotation of pre-lecture reading whose purpose is to enable students gain better understanding of reading material (OEIT - MIT, 2019), which facilitates the active and collaborative students' participation as a strategy to understand texts. In this regard, Karger (2019) states that NB allows learners to read the information sent by their teachers and include their questions or comments as well as reply to their partners' participation. Additionally, this tool helps communication between teacher and students due to the fact that they can interact each other by discussing some aspects related to the analyzed material.

The technological characteristics of NB allow users to do all their activities in the margins of online lecture notes. The activities can include making notes (participants highlight relevant ideas to draw their partners' attention), asking questions (students highlight information to ask their class about it), seeing trouble spots (teachers know the parts of the material where students need more explanation), and answering questions (students reply any question if they know the answer). Regarding the advantages of NB, it allows to add extra materials such as sample videos, soundtracks, or other texts to specific parts of the reading material. Additionally, NB engages students more deeply in reading, works as a resource for practicing, and allows participants to know their partners' opinion about different parts of the text before classes (nb, 2019).

\section{Previous Studies}

Research on the use of online annotation tools has been conducted regarding doing collaborative work and improving reading and writing skills but not on enhancing academic performance in the educational field. Zyto et al. (2012) worked on a study in which NB was used in 55 classes at 10 universities. Students used $\mathrm{NB}$ to maintain threaded discussions in the margins of online class material. In order to know its efficacy, the annotation practices were analyzed and discussed. The study concluded that the comments displayed in the margins drew students' attention to important comments and encouraged them to answer back. Finally, the physical location of comments about a specific topic benefited an organized discussion and learning because students discussed topics in sequence; this allowed them to aggregate related threads and consider them together. 
Yang, Yu and Sun (2013) conducted a study whose purpose was to improve school children's reading literacy by exploring the effect of a collaborative annotation system called Sharing Unique Reading Feeling (SURF) on Chinese primary school students. The study was an experimental one in which two teachers and 66 students divided into two groups participated. Students were administered pre and post-tests. During the study, the experimental group used SURF for annotating and sharing information. At the end, the participating teachers were interviewed. Results were analyzed from a comparative point of view. The findings reported that reading performance is promoted by the collaborative annotation supported by SURF. It enhances reading levels and develops the higher-level cognitive abilities such as analyzing, summarizing and evaluating Johnson, Archibald and Tenenbaum (2010) studied the potential of the Annotation Model-Learning System tool (SAM-LS) for improving teaching and learning in Freshman English classes. The instruments used were five articles and three questionnaires based on those articles. Each one of the questionnaires measured cognitive skills such as reading comprehension, critical thinking and metacognition. The articles and questionnaires were administered to two hundred and fifty-four students enrolled in a southeastern community college. Students were also tested before and after the intervention. Additionally, 6 instructors participated in this study. The findings of the experiment evidence that there was a significant relation between the use of SAMLS and reading comprehension, while meta-cognition was better developed; however, critical thinking did not show such effect.

Hwang, Shadiev and Huang (2010) designed a Virtual Pen (VPen) - a multimedia web annotation tool - and tested its efficacy for improving students' writing and speaking skills by using an experimental approach. Twenty-seven third-grade students from high school participated in this experiment. Students were asked to create and share annotations, and give feedback to peers' work. Furthermore, the authors investigated the students' perception toward the design and usage of learning online activities and VPen system. They found a significant correlation between students' VPen use and their performance in productive skills. Regarding students' perceptions, VPen was seen as an easy-to-use and interactive annotation tool.

\section{METHOD}

In the present study, a quasi-experimental design was used because the two classes were taken as the two samples for the experimental and control group respectively, so we used purposeful sampling. According to Creswell (2015), this sampling technique is useful for selecting participants whose characteristics can provide the necessary information for the study.

\section{Participants}

Ninety-eight university pre-service teachers from two classes participated in this study. They were taking the Educational Research course in the seventh semester of the English Program at a distance university in Ecuador. The purpose of this program is to train pre-service teachers so they can become EFL teachers. One class was taken as the experimental group (50 pre-service teachers) and the other one as the control group (48 pre-service teachers). The participants were adult learners, fifty-one of them were female and forty-seven male. Their mother tongue is Spanish, and they had a B1 English proficiency level, according to the Common European Framework of Reference for Languages: Learning, Teaching, Assessment (CEFR) (Council of Europe, 2001).

\section{Instruments}

Pre and Post-Tests

A pre-test, which was graded out of 20 points, containing 15 multiple-choice items was administered at the beginning of the semester to measure the students' general knowledge in regards to the subject content. At the end of the semester, a post-test - with a similar structure as the pre-test - was also given to both groups in order to measure their progress in the acquisition of knowledge related to the contents of the course. 


\section{Questionnaire}

A 14-item questionnaire was directed to participants from the experimental group in order to know their perceptions about the use of $\mathrm{NB}$ and the activities that were carried out on this tool during the semester. This questionnaire was based on a 4-point Likert scale (strongly disagree, disagree, agree, strongly agree).

The instruments used in this study were piloted with 25 university students from the English major. Some corrections were implemented in the pre and post-test as well as the questionnaire after receiving some feedback from the students who answered the test and responded to the questionnaire. The results of the students' answers to the questionnaire were entered into SPSS in order to obtain the Cronbach's alpha. The Cronbach's alpha obtained was 0.7 , which is acceptable.

\section{Procedure}

Throughout the process, both groups (experimental and control) learned by doing the same synchronous and asynchronous activities by using the "Entorno Virtual de Aprendizaje" (EVA) platform, a Moodle-based E-learning platform used by the university pre-service teachers under study. Unlike the control group, the experimental one used the NB tool as an extra resource to learn the contents of the course.

The intervention started with the administration of a pre-test to both experimental and control group in order to diagnose the participants' previous knowledge of the subject. After that, the pre-service teachers who belonged to the experimental group, were introduced to the use of NB tool by means of a videoconference; resources such as PDF documents, PowerPoint presentations and links were also provided in order for them to learn more about this tool.

Afterwards, the participants from both groups had to read information related to the contents to be studied. This information was uploaded on the EVA platform every week by the instructor. In the case of the experimental group, besides reading the material on EVA, they were required to read that material and interact on NB by highlighting relevant information, as well as posting discussions and comments about the documents studied. Later on, the instructor provided feedback to both groups by commenting on the preservice teachers' participation. The purpose of these activities was to promote interaction among participants and between participants and instructor.

In order to assess learning, both groups had to submit PowerPoint presentations, summaries of chapters, and different hands-on activities during the semester using the Entorno Virtual de Aprendizaje (EVA). At the end of the semester, pre-service teachers were given a post-test with the purpose of measuring their progress in terms of the acquisition of the contents of the course.

The data collected from the pre and post-tests (grades) were organized and prepared for the statistical analysis, which was performed by applying the student's unpaired t-test (for two samples) in order to test statistically significant differences for both groups regarding the pre-test and post-test. The confidence level was $95 \%$. As for the questionnaire (responses), the information was tabulated and the frequencies, percentages and mode were obtained so the most frequent responses can be viewed.

\section{RESULTS}

As observed in Table 1 below, there is no statistically significant difference between the control and the experimental group ( $p>0.05)$ in the pre-test, which indicates a similar level of knowledge of both groups at the beginning of the semester.

Table 1. Results Pre-test

\begin{tabular}{lll}
\hline Statistics & Control group & Experimental group \\
\hline Mean & 12.34 & 12.81 \\
$\mathrm{SD}$ & 1.392 & 1.690 \\
\hline $\mathrm{p}=0.1402$ & & \\
\hline
\end{tabular}


Table 2 displays the statistical values obtained for the post-test. A noteworthy improvement can be observed because the means of the post-tests are higher than the ones of the pre-tests in both groups. As for the comparison of the results of the post-test between the control and experimental group, the difference is statistically significant $(\mathrm{p}<0.0141)$, so the experimental group has experienced a remarkable improvement in their academic performance.

Table 2. Results Post-test

\begin{tabular}{lll}
\hline Statistic & Control group & Experimental group \\
\hline Mean & 15.9 & 16.68 \\
$\mathrm{SD}$ & 1.409 & 1.641 \\
\hline $\mathrm{p}=0.0141$ & & \\
\hline
\end{tabular}

Table 3. Pre-service teachers' perceptions about using NB

\begin{tabular}{lc}
\hline Items & Mo \\
\hline 1. I feel motivated to use the NB tool to do activities related to my course. & 3 \\
2. The NB tool facilitates the completion of the proposed activities. & 3 \\
3. The extracurricular activities proposed to be done on the NB tool are appealing and enjoyable. & 3 \\
4. My interest in the course has increased as a result of using the NB tool. & 3 \\
5. It is interesting to comment my classmates' participation by using the NB tool. & 3 \\
6. The NB tool allowed me to effectively interact with my teacher and classmates. & 3 \\
7. The NB tool was useful to acquire knowledge. & 3 \\
8. Knowledge is easily acquired by means of the NB tool. & 4 \\
9. The use of resources on the NB tool made learning dynamic (interactive) & 4 \\
10. The NB tool was innovative to learn the course. & 3 \\
11. NB is a friendly and intuitive tool (easy-to-use). & 3 \\
12. It has been beneficial to ask questions and receive answers by using NB tool. \\
13. The feedback received on NB has been useful for learning. \\
14. You learn faster by using the NB tool.
\end{tabular}

After the intervention, the participants answered a questionnaire on the use of NB. Regarding statement 1 , the results show that they agree on being motivated to use NB to work on activities related to their course ( $\mathrm{Mo}=3 ; 42.86 \%$ of students). Participants also believe that NB facilitates the completion of activities (Mo $=3 ; 53.06 \%)$.

With respect to statement 3,51.02\% of participants considers that NB makes homework enjoyable and appealing $(\mathrm{Mo}=3)$. In addition, NB increases participants' interest on the course $(\mathrm{Mo}=3 ; 53.06)$, as mentioned in statement 4 .

This tendency to agree on the items is also shown in statement 5 since $40.82 \%$ (Mo=3) of participants finds it interesting to comment their classmates posts on NB. Actually, $64.29 \%(\mathrm{Mo}=3)$ agrees that this tool allows instructor-student, and student-student interaction throughout the course.

In statement 7 , participants agree that this tool is useful to acquire knowledge ( $40.82 \%$; $\mathrm{Mo}=3)$. In fact, in statement 8 , they point out that knowledge is easily acquired through $\mathrm{NB}(\mathrm{Mo}=4 ; 32.65 \%)$.

As mentioned in statement $9,35.71 \%$ of the participants believes that the resources that NB incorporates (YouTube videos, HTML and PDF files, and PPTs) help them learn interactively (Mo=4). In fact, 53.06 $\%(\mathrm{Mo}=3)$ of learners considers $\mathrm{NB}$ an innovative learning tool in the course, as described in statement 10. Regarding statement 11 , most of the participants $(44.9 \%-\mathrm{Mo}=3)$ believe that NB was a user-friendly and intuitive tool.

Posting questions and answers by means of NB has been useful for learning the contents of the course, according to $37.76 \%$ of participants in terms of statement 12 . Participants $(42.2 \%-\mathrm{Mo}=4)$ also think that the feedback provided on NB (statement 13) has been useful to learn. 
Despite the participants' tendency to agree or totally agree with most of the items in the questionnaire, most of them disagree on statement 14 , which states that one can learn faster when using NB $(42.86 \% ; \mathrm{Mo}=4)$.

\section{DISCUSSION}

Before the intervention, both experimental and control group possessed a similar background knowledge regarding the contents of the subject they were about to study (control group: 12.34/20 - experimental group: 12.81/20); this similarity means that both samples were comparable. The scores of the pre-test previously shown, according to the university standards, indicate that pre-service teachers in both groups had very basic knowledge.

As expected, both groups improved their academic performance after finishing the course (control group: 15.9 /20 - experimental group: 16.68/20); this improvement means that pre-service teachers achieved good knowledge of the contents of the course. There is also a statistically significant difference that can be noticed in the results of the post-test, which favors the experimental group. Therefore, the academic performance of the experimental group improved as a result of using NB; thus, allowing participants to do interactive and innovative activities. These results show some similarities in terms of the effectiveness of NB for purposes such as asking questions and discussing the contents of a course (Wright, Zyto, Karger \& Newman, 2013). However, the present study adds the provision of feedback to pre-service teachers through the NB tool for academic purposes, which is an issue that has been applied in studies on other annotation tools with successful results (e.g. Yeh, Hung \& Chiang, 2017).

Furthermore, the information provided by the participants' responses to the questionnaire revealed that the use of NB to do the activities in class was motivating. The use of technology made the lessons more interesting than teaching traditionally; this was supported by the participants' opinions who believe that they can use NB to be more creative to complete academic activities. Additionally, the interactive environment provided by $\mathrm{NB}$ and the resources that can be added make the assignments more enjoyable, interesting, and appealing as it is stated in a study by Sun and Gao (2017) in which annotation tools are considered as alternatives to enhance participants' interaction. Furthermore, Novak, Razzouk and Johnson (2012) manifest that annotation tools have had positive effects on instruction due to an increase in the level of motivation.

$\mathrm{NB}$ is also considered a user-friendly and intuitive tool that allows teachers and learners to provide and receive feedback accordingly. All the aforementioned features boost and facilitate the acquisition of new knowledge; however, pre-service teachers do not believe that NB can help them learn faster. All the aforementioned features boost and facilitate the acquisition of new knowledge as it is also stated in a study by Krouska, Troussas, and Virvou, (2018) in which they claim that incorporating a social annotation tool in digital learning improves the understanding and memorization of materials; however, in our study, pre-service teachers do not believe that NB can help them learn faster.

\section{CONCLUSIONS}

After analyzing the results of the post-test in both, experimental and control group, we conclude that NB was an effective tool to enhance pre-service teachers' academic performance in a distance program. This effectiveness is reflected on the statistically significant differences found in the scores of the post-test of both groups, favoring the experimental group.

Regarding pre-service teachers' perceptions about using NB, they think that this tool is motivating, interesting, interactive, easy-to-use and intuitive. The attributes of this tool allowed them to enhance their academic performance in distance courses.

The study recommends that future research should focus on analyzing on line annotation tools in EFL and ESL contexts, since that is the program the participants of this study were enrolled. 


\section{BIODATA and CONTACT ADDRESSES of AUTHORS}

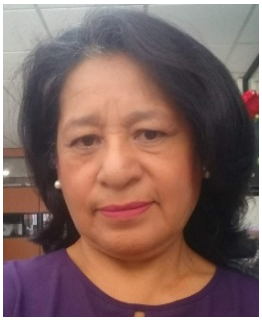

Dr. Carmen BENITEZ, has a Ph.D. in English Philology at the Universidad Nacional de Educación a Distancia (UNED) de Madrid, Spain. She holds a degree in Educational Sciences: Educational Planning and Research from Universidad Tecnica Particular de Loja (UTPL). She also has a degree in English Teaching English. She is a Professor at Universidad Tecnica Particular de Loja (UTPL), Ecuador for about 23 years. She coordinates the EFL Tech research group at UTPL and she has been co-author of some important indexed articles.

\section{Carmen BENITEZ}

Universidad Tecnica Particular de Loja, Postal 1101608

Address: San Cayetano Alto, calle Marcelino Champagnat, Loja, Ecuador

Phone: 593073701444

E-mail: cdbenitez@ytpl.edu.ec

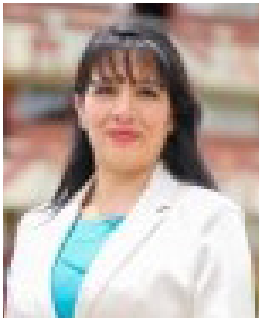

Dr. Ana QUINONEZ, is a professor at the Education Department of Universidad Tecnica Particular de Loja, at the faculty of English. She has a Master degree in Educational Technology: e-Learning and knowledge Management at Universidad Rovira i Virgili, and has a Doctoral degree in Educational Research from Universidad Nacional de Loja. She has 14 years of teaching experience at the higher education level and she has been co-author of some important indexed articles.

\section{Ana QUINONEZ}

Educational Sciences Department

Universidad Tecnica Particular de Loja, Postal 1101608

Address: San Cayetano Alto, calle Marcelino Champagnat, Loja, Ecuador

Phone: 593073701444

E-mail: alquinonez@utpl.edu.ec

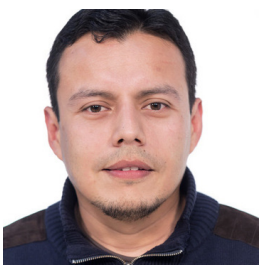

Dr. Paul GONZALEZ, Ph.D. in Language Acquisition at the Basque Country University, Spain. Master of Science in Teaching English as a Foreign Language at Nova Southeastern University of Florida U.S.A. Master of Teaching English as a Foreign Language at UTPL. Professor for fourteen years at Universidad Tecnica Particular de Loja (UTPL), Ecuador. Co-author of articles in indexed journals.

Paul GONZALEZ

Educational Sciences Department

Universidad Tecnica Particular de Loja, Postal 1101608

Address: San Cayetano Alto, calle Marcelino Champagnat, Loja, Ecuador

Phone: 593073701444

E-mail:pfgonzalez@utpl.edu.ec 


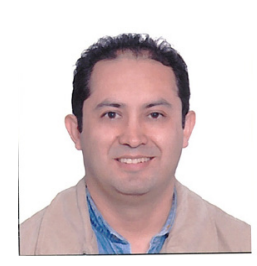

Cesar OCHOA, holds a Master's Degree in Teaching English as a Foreign Language at NOVA Southeastern University of Florida U.S.A and Universidad Tecnica Particular de Loja (UTPL). He currently works for UTPL in Ecuador. He has worked as an EFL teacher for more than 17 years. He has been the TOEFL iBT Administrator at the UTPL test center. He has been the Head of the Research and Services English Center at UTPL and he has been co-author of some indexed journals.

\section{Cesar OCHOA}

Educational Science Department

Universidad Tecnica Particular de Loja, Postal 1101608

Address: San Cayetano Alto, calle Marcelino Champagnat, Loja, Ecuador

Phone: 593073701444

E-mail: caochoa@utpl.edu.ec

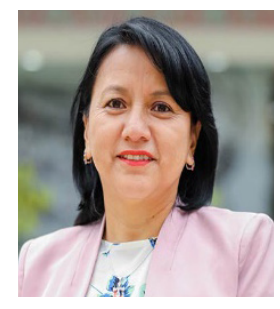

Alba VARGAS, Master in Education with a specialization in teaching English as a foreign language at NOVA Southeastern University -Universidad Tecnica Particular de Loja. Master in Distance Education at Universidad Tecnica Particular de Loja. English teacher at Universidad Tecnica Particular de Loja. More than 15 years of experience as a high school and university EFL teacher. Currently, English Professor at UTPL of different subjects like: Curriculum and materials, Reading and Writing, Educational Research among others. Academic coordinator of the English major at Universidad Tecnica Particular de Loja. Research interests enclose areas related to EFL teaching and Learning, technology in $\mathrm{EFL}$, and language curriculum design and evaluation.

\section{Alba VARGAS}

Educational Sciences Department

Universidad Tecnica Particular de Loja, Postal 1101608

Address: San Cayetano Alto, calle Marcelino Champagnat, Loja, Ecuador

Phone: 593073701444

E-mail: cdbenitez@ytpl.edu.ec

\section{REFERENCES}

Azouaou, F., Chen, W., Desmoulins, C. (2004). Semantic annotation for learning material. In: Proceedings of Semantic Web and e-Learning Workshop, Adaptive Hypermedia, AH'04, Vol. 2. CS-Report 04-19. Eindhoven University of Technology, (pp. 359-364).

Borham-Puyal, M., \& Olmos-Miguelanez, S. (2011). Improving the use of feedback in an online teachinglearning environment: An experience supported by Moodle. US-China Foreign Language, 9(6), 371-382.

Bottoni P., Levialdi S., Rizzo P. (2003). An analysis and case study of digital annotation. In: BianchiBerthouze N. (eds) Databases in Networked Information Systems. DNIS 2003. Lecture Notes in Computer Science, vol 2822. Springer, Berlin, Heidelberg. doi: https://doi.org/10.1007/978-3540-39845-5_18.

Burghardt, M. (2012). Usability recommendations for annotation tools. In Proceedings of the Sixth Linguistic Annotation Workshop (pp. 104-112). Association for Computational Linguistics.

Creswell, J. W. (2015). Educational research: Planning, conducting, and evaluating quantitative and qualitative research. New Jersey: Upper Saddle River.

Gao, F. (2013). A case study of using a social annotation tool to support collaboratively learning. The Internet and Higher Education, 17, 76-83. doi: https://doi.org/10.1016/j.iheduc.2012.11.002. 
Glover, I., Xu, Z., \& Hardaker, G. (2007). Online annotation-Research and practices. Computers \& Education, 49(4), 1308-1320. doi: https://doi.org/10.1016/j.compedu.2006.02.006.

Hwang, W. Y., Shadiev, R., \& Huang, S. M. (2010). Effect of multimedia annotation system on improving English writing and speaking performance. In International Conference on Technologies for E-Learning and Digital Entertainment (pp. 1-12). Springer, Berlin, Heidelberg.

Hwang, W.Y., Wang, C. Y., \& Sharples, M. (2007). A study of multimedia annotation of Web-based materials. Computers \& Education, 48(4), 680-699. doi: https://doi.org/10.1016/j.compedu.2005.04.020.

Johnson, T. E., Archibald, T. N., \& Tenenbaum, G. (2010). Individual and team annotation effects on students' reading comprehension, critical thinking, and meta-cognitive skills. Computers in human behavior, 26(6), 1496-1507.doi: https://doi.org/10.1016/j.chb.2010.05.014.

Karger (2019) https://oeit.mit.edu/gallery/projects/nb-pdf-annotation-tool/

Kawase, R., Herder, E., \& Nejdl, W. (2009). A comparison of paper-based and online annotations in the workplace. In European Conference on Technology Enhanced Learning (pp. 240-253). Springer, Berlin, Heidelberg.

Krouska, A., Troussas, C., \& Virvou, M. (2018, July). Social Annotation Tools in Digital Learning: A Literature Review. In 2018 9th International Conference on Information, Intelligence, Systems and Applications (IISA) (pp. 1-4). IEEE.

Miller, K., Lukoff, B., King, G., \& Mazur, E. (2018). Use of a social annotation Platform for Pre-class reading assignments in a Flipped Introductory Physics class. In Frontiers in Education (3) 8. Frontiers. doi: https://doi.org/10.3389/feduc.2018.00008.

Murugaiah, P., \& Thang, S. M. (2010). Development of interactive and reflective learning among Malaysian online distant learners: An ESL instructor's experience. The International Review of Research in Open and Distributed Learning, 11(3), 21-41. doi: https://doi.org/10.19173/irrodl.v11i3.84.

nb (2019) http://nb.mit.edu/about/

Nokelainen, P., Kurhila, J., Miettinen, M., Floreen, P., \& Tirri, H. (2003). Evaluating the role of a shared document-based annotation tool in learner-centered collaborative learning. In Proceedings 3rd IEEE International Conference on Advanced Technologies (pp. 200-203). IEEE. doi: https://doi. org/10.1109/ICALT.2003.1215056.

Novak, E., Razzouk, R., \& Johnson, T. E. (2012). The educational use of social annotation tools in higher education: A literature review. The Internet and Higher Education, 15(1), 39-49. doi: https://doi. org/10.1016/j.iheduc.2011.09.002.

Nunes, B. P., Kawase, R., Dietze, S., de Campos, G. H. B., \& Nejdl, W. (2012). Annotation tool for enhancing e-learning courses. In International Conference on Web-Based Learning pp. 51-60. Springer, Berlin, Heidelberg. doi: https://doi.org/10.1007/978-3-642-33642-3_6

OEIT - MIT (2019) https://oeit.mit.edu/category/keywords/pdf/index.html

Shaked, H., Schechter, C., \& Michalsky, T. (2018). Collaborative learning from personal cases in a principal preparation programme. International Journal of Leadership in Education, 21(4), 479-490. doi: https://doi.org/10.1080/13603124.2016.1151942.

Sun, Y., \& Gao, F. (2017). Comparing the use of a social annotation tool and a threaded discussion forum to support online discussions. The Internet and Higher Education, 32, 72-79. doi: 10.1016/j. iheduc.2016.10.001

Tezci, E. (2009). Teachers' effect on ICT use in education: The Turkey sample. Procedia-Social and Behavioral Sciences, 1(1), 1285-1294. doi: https://doi.org/10.1016/j.sbspro.2009.01.228.

Wright, L. K., Zyto, S., Karger, D. R., \& Newman, D. L. (2013). Online Reading Informs Classroom Instruction and Promotes Collaborative Learning. Journal of College Science Teaching, 43(2), 44-53. 
Yang, X., Yu, S., \& Sun, Z. (2013). The effect of collaborative annotation on Chinese reading level in primary schools in China. British Journal of Educational Technology, 44(1), 95-111. doi: https:// doi.org/10.1111/j.1467-8535.2011.01277.x

Yeh, H. C., Hung, H. T., \& Chiang, Y. H. (2017). The use of online annotations in reading instruction and its impact on students' reading progress and processes. ReCALL, 29(1), 22-38. doi: https://doi. org/10.1017/S0958344016000021.

Yeh, S. W., \& Lo, J. J. (2009). Using online annotations to support error correction and corrective feedback. Computers \& Education, 52(4), 882-892. doi: https://doi.org/10.1016/j.compedu.2008.12.014.

Zyto, S., Karger, D., Ackerman, M., \& Mahajan, S. (2012). Successful classroom deployment of a social document annotation system. In Proceedings of the SIGCHI Conference on Human Factors in Computing Systems (pp. 1883-1892). ACM. doi: https://doi.org/10.1145/2207676.2208326. 